\title{
EL HUMANISMO DE JOVELLANOS
}

Al definir el humanismo en nuestros días, distinguía Alfonso Reyes entre el significado actual del término y su sentido tradicional: "El término humanismo en la Europa moderna vino a significar simplemente el estudio de la Antigüedad clásica. Hoy se vuelve al concepto de la responsabilidad social en el nuevo humanismo" (Junta de sombras, México, 1949, p. 327). En este concepto de la responsabilidad social insistieron ya los pensadores humanistas del siglo xvirI, tanto americanos como españoles, y es lo que más los distingue de los humanistas del Renacimiento -aunque no de Juan Luis Vives. Desde Vives hasta Reyes, a través de Jovellanos y sus contemporáneos ilustrados, el humanismo, lejos de ser el culto erudito y estático a la Antigüedad clásica, es un proceso vivo de liberación del espíritu humano individual y colectivo. En los autores clásicos se buscaban, desde luego, normas y modelos; pero éstos servían sobre todo para apoyar la nueva visión del hombre, para reafirmar su dignidad y su valor autónomo. En el estudio de los clásicos veían los pensadores de la Ilustración un medio de reformar al hombre, de formar de una manera totalmente nueva su espíritu, dándole visión crítica e independencia. Si en el siglo xvi se trata de la formación libre del espíritu del hombre, en el xvirI se destaca la nueva preocupación por "la humanidad", y se habla de la reforma de "los hombres" mediante la ilustración, entendida ésta ya no como un fin en sí, sino como medio de conseguir la reforma de la sociedad.

Un humanista del siglo xvin, como Jovellanos, buscaba en los clásicos antiguos normas estéticas y valores éticos, sí, pero también "autoridades" para justificar los nuevos estudios científicos fundados exclusivamente en la observación directa de la realidad y en la experiencia, sin las cuales sería imposible librar la razón del anquilosamiento escolástico que padecía. Los clásicos servían para cimentar la nueva fe en la inteligencia humana como instrumento de reforma y de progreso moral y material. Jovellanos, sin embargo, no veía este progreso intelectual y material, esta perfectibilidad ética de la sociedad, como hechos inevitables, automáticos, sino sólo como bienes posibles mediante el esfuerzo constante y fervoroso de un grupo de individuos ilustrados oue se dedicaran a tales objetos. Todas esas 
ideas se encontraban, en lo esencial, en distintos pasajes de las obras de Juan Luis Vives, el cual, en cierta página escrita en Brujas, había deplorado que sus libros fueran poco leídos y, sobre todo, poco comprendidos en su patria, donde más provecho podría y debía sacarse de ellos. Sus compatriotas tardarían todavía dos siglos en conocerlos a fondo, pero entonces sí habrían de apurar hasta la última gota su profunda sabiduría.

No es un azar que en el siglo xvirr salgan a luz por primera vez versiones castellanas de algunas obras de Vives, y que se publiquen en repetidas ediciones a través de todo el siglo. En 1723, el valenciano Cristóbal Coret y Peris traduce del latín los célebres Diálogos en una prosa española cuya viveza y hermosura fue alabada por Mayans, y que todavía hoy leemos con placer; en 1772, Cerdá y Rico reimprime la versión castellana que había hecho Cervantes de Salazar de la Introducción a la sabiduria (versión publicada originalmente en 1546 , junto con obras de Pérez de Oliva y Luis Mexía, en un hermoso tomo dedicado a Hernán Cortés); y en 1781 sale a la luz, también en Valencia, el tratado Del socorro de los pobres, tema que apasionaba a los españoles ilustrados casi tanto como el pedagógico de los Diálogos. Para la magnífica edición valenciana de Ope$r a$ de Vives (1782-9o, ocho tomos) escribió Mayans en latín la biografía del gran humanista del Renacimiento español, a quien más tarde dedicaría un importante estudio otro compatriota, Juan Pablo Forner. Todos los pensadores españoles de la época leían a Vives y repetían sus ideas y observaciones, adaptándolas a las circunstancias nuevas -en muchos aspectos no tan nuevas- de los últimos lustros del siglo xvirr. En este caso, como en muchos otros, la Ilustración española es un re-Renacimiento, una continuación directa de la manera de pensar y sentir del siglo xvr.

Jovellanos tiene, como Vives, temperamento de educador, y cree, como él, que la educación debe ayudar a desarrollar en armónico conjunto la personalidad humana, a formar al hombre íntegro, cuerpo y espíritu, inteligencia y sentimiento. Los dos anhelan armonizar en su enseñanza el humanismo con el cristianismo, el máximo perfeccionamiento individual con la máxima preocupación por las obligaciones sociales, la ciencia desinteresada con el conocimiento útil a todos los hombres para su conducta y su felicidad. Ambos ven en la verdadera educación la posibilidad de un renacer, de una reforma -que significa el hallazgo de formas sociales y religiosas primarias, más auténticas, más puras. De ahí arranca la crítica social de ambos, es decir, la ironía de Vives y la sátira de Jovellanos. Cuando este último, en la "Sátira a Arnesto", censura el majismo de la nobleza:

¿Ves, Arnesto, aquel majo en siete varas de pardomonte envuelto, con patillas 
de tres pulgadas afeado el rostro, magro, pálido y sucio, que al arrimo de la esquina de enfrente nos acecha con aire sesgo y baladí? Pues ése, ése es un nono nieto del rey Chico...,

lo que hace es poner de relieve el violento contraste que existe entre el majo del día y sus gloriosos antepasados, y satirizar su ignorancia, su ociosidad y su total falta de sentido de responsabilidad, puesto que en vez de servir de ejemplo al pueblo, de elevarlo, de conducirlo en las más heroicas hazañas, como los antiguos Ponces y Guzmanes, lo corrompe remedando sus peores costumbres. Contra la ignorancia de los nobles arremetía ya Vives en el diálogo sobre "La escritura", donde el Maestro declara a sus discípulos Manrique y Mendoza que aunque lleven nombres que manifiestan nobleza, sólo serán nobles de verdad si adornan sus entendimientos con las artes dignas de los bien nacidos. Vives zahiere a la loca nobleza que desdeña las artes y las ciencias, a los hombres de ilustre cuna que consideran el saber como la cosa más abatida y más vil. A esos tales, el Maestro no vacila en llamarlos "el vulgo de la nobleza". Al oír esto, pregunta Mendoza: “¿Cómo son vulgo si son nobles?”, y contesta su compañero Manrique diciendo que la verdadera diferencia entre la nobleza y el vulgo no está en los vestidos y las riquezas, sino en "el buen modo de vivir y el entero y cabal juicio de las cosas". Vives reitera en la Introducción a la sabiduria que la auténtica nobleza no nace de la estirpe sino de la virtud, y advierte: "Locura es gloriarte de haber tenido un padre bueno si tú eres malo y si con tus ruines obras pones desdoro y mancilla en la nobleza de tu linaje". Este mismo concepto de la nobleza se ha de repetir en la España del siglo xvni, desde Feijóo hasta Cadalso y Jovellanos. Así Madramany y Calatayud, en su Discurso sobre la nobleza de las armas y las letras (Madrid, 1790), afirma que la nobleza no puede ser patrimonio ajeno o heredado, sino que cada cual tiene que hacerse su propia nobleza, y cita en su apoyo unos versos de Juan de Mena (Coplas de los siete pecados):

De muy gran tiniebla ofusca

las leyes de gentileza quien no hace la nobleza, y en sus pasados la busca.

El noble, pues, tiene el deber de forjarse su propia nobleza para sí mismo y para su linaje. Jovellanos sostiene que la responsabilidad del noble es mayor que la de los demás, puesto que se extiende no sólo a la familia, sino a la sociedad. La nueva nota es la económica: el noble tiene la obligación de ser útil a los labradores, los cuales lo llevan a cuestas como carga; si no, es un zángano ocioso e irrespon- 
sable, indigno del "continuo sudor" que derrama el pueblo sobre sus tierras.

El mismo reproche de ociosidad e inutilidad pública es la base de la crítica antimonástica de Jovellanos y de todos sus contemporáneos ilustrados, como el valiente editor de la revista periódica $E l$ Censor, que era suprimida y retirada de la circulación cada vez que criticaba a los elementos inútiles de la sociedad. Jovellanos zahería ciertos usos y costumbres populares que pasaban por religiosos, y a los curas y frailes que con tales medios explotaban la superstición popular; pero raras veces publicaba esta crítica, en algún artículo, en alguna poesía satírica sin firma; prefería hacerla en cartas, que eran el medio más seguro de escribir para el porvenir, y en sus Diarios, que reflejan su visión de la España que le rodeaba a la vez que su pensar y sentir sobre todos los problemas y conflictos nacionales.

El panorama que nos muestra la lectura de estos Diarios es vasto y complejo: un paisaje sublime, un pueblo fiel a sus tradiciones y capaz de esfuerzos inverosímiles, un país que ha tenido un pasado magnífico, del cual queda amplio testimonio en su gran tesoro de monumentos artísticos de todas las épocas y de todos los estilos, y en los innumerables documentos que el autor va recogiendo en los archivos, pruebas, todas éstas, de que el país cuenta plenamente con la posibilidad de volver a ser grande en el porvenir; pero también nos queda una visión sombría de lugares despoblados, sucios y tristes, de moradores tristes y desaliñados, de campos sin plantíos de árboles, tierras baldías, propietarios ausentes, colonos infelices que con su trabajo ímprobo no ganan lo suficiente para subsistir, y muchos ociosos e inútiles mayorazgos y numerosísimos frailes que viven del trabajo de estos míseros agricultores. En el pueblo de Tineo apunta Jovellanos: "al convento, ruin, pobre; mantiene, sin embargo, treinta frailes que arruinan al pueblo..." (Diarios, ed. J. Somoza, Oviedo, 1953-54, t. 2, p. 18). Al parar en un pueblo, siempre anota el número de parroquias y el de habitantes, y enumera los conventos. Así en el pueblo de Durango, donde estuvo el 20 de agosto de 1791 (Diarios, t. 1, p. 168):

Hay aquí un gran convento de agustinos, edificado poco ha, aunque fundado en el siglo pasado. Era antes un hospicio de cuatro o cinco frailes que vivían en una pequeña casa; ya son catorce; no tienen renta y viven de las limosnas. Item dos conventos de monjas, agustinas y franciscanas, ambas propietarias, aunque, según dicen, pobres...

O el año anterior, en Mayorga: “50o vecinos; 7 parroquias; 24 sacerdotes; un convento de San Francisco con 17 frailes; uno de Santo Domingo con 4; otro de monjas dominicas, ricas" (t. 1, p. 120). En el pueblo natal de Berruguete -donde nadie da razón del gran 
artista - hay "setecientos sesenta vecinos útiles, contribuyentes" y cuatro parroquias, una de ellas con siete beneficiados, otra con cuatro... (t. 2, p. 109). Al llegar a Arbas años después, en 1797, tras una subida agria por "laderas en extremo pendientes", va a ver la iglesia colegial, "obscura, húmeda, fría, insufrible", y se pregunta (t. 2, pp. $44^{6-447):}$

¿De qué sirve en este desierto tal congregación de clérigos secuestrados ['segregados'] del trato humano? ¿De qué las limosnas dadas a holgazanes o vagamundos? ¿De qué el llamado hospital, que sólo sirve para alojarlos y atraerlos? ¿No estaría mejor trasladado a un lugar poblado del camino? De esto hablé mucho con el $\mathrm{Abad}$; pero, aunque lo desea, no tiene espíritu para emprenderlo. Al cabo, mejor pensada estaba la supresión...

Apunta unas coplas populares que ha oído cantar y que muestran que el pueblo no tiene mejor concepto de los frailes (t. 1, p. 234):

De gorriones, curas y frailes, líbrenos Dios de estas tres malas aves.

Los gorriones se comen el trigo,

y los curas se beben el vino,

y los frailes retozan las mozas:

líbrenos Dios de estas tres malas cosas.

Las ha oido cantar con evidente placer, el mismo con que antes escuchó a Samaniego recitarle su "Descripción del Desierto de Bilbao", cuando hizo una visita al fabulista en Tolosa. No obstante, el sentir de Jovellanos en estos asuntos es bastante distinto del de Samaniego y de los enciclopedistas franceses, y distinto, sobre todo, del anticlericalismo vulgar del siglo xix. Lo que le duele a Jovellanos es que los muchos curas y frailes que viven a costas del pueblo y que debían y podrían dirigirlo espiritualmente, elevarlo, instruirlo, no sólo no lo hacen, sino que lo mantienen en su ignorancia y hasta se la cultivan. Así al llegar al pueblo de Camposagrado, después de observar en el camino veinticuatro cráteres o "tazas" de figura esférica, demasiado pequeños para volcanes, pregunta a los naturales qué son, pero éstos sólo pueden contarle la tradición según la cual el infante Pelayo escondió allí veinticinco hombres en cada uno y atacó desde esa "emboscada" a los moros, destruyéndolos. Y su comentario es: "Esta hablilla, el nombre de Camposagrado, la aparición creída de la imagen de este nombre y la propensión de la ignorancia a buscar en todo origenes maravillosos, han fomentado la superstición del vulgo, que aún dura" (t. 1, pp. 273-274).

Jovellanos reprueba, como Erasmo, el culto de las imágenes, porque ve en él una manifestación pagana que degrada la religión cristiana a la vez que fomenta la superstición del vulgo. Estando en Gijón le sacan de quicio las rogativas por el agua; el 26 de agosto 
de 1795 apunta, irritado, que se ha encontrado en la calle con el Rosario, y al día siguiente hace este comentario sarcástico: "Agua abundante toda la mañana, con general alegría. ¡Vivan los clérigos! Machacón dice que le arrancaron sus voces. En efecto, anoche ponía sus berridos en el cielo" (t. 2, p. 156). Un año antes, el 31 de agosto de 1794, se había referido a otra rogativa (t. 1, pp. 480-481):

Por la tarde vimos pasar la procesión de rogativa, numerosa, en silencio y bien ordenada; los regidores, con coronas y sogas, cosas ridículas, atendida su representación. A mi ver, los metió en eso el cura, y a él, Machacón. Acuérdome del soneto que hice poner en el Diario de Madrid sobre el Rosario de los comediantes. Acababa así: "iAl fin, en esta gente, todo es farsa!"

"Farsa" no sólo de los comediantes, sino también del clero. A Jovellanos le chocaba profundamente que degenerara en eso un acto religioso. El soneto aludido había aparecido, sin firma, en el Diario de Madrid del miércoles 13 de agosto de 1788 , precedido de una Carta, igualmente anónima, fechada en Madrid a $1^{\circ}$ de agosto del mismo año, y dirigida por "un quidam a un amigo suyo, en que le describe el Rosario de los Cómicos de esta Corte":

QQué Rosario, amigo mío! ¡qué Rosario tan magnífico el de Nra. Sra. de la Novena! Anoche le vi, y aún no he salido de mi admiración. ¿Qué música! iqué faroles! iqué estandarte! iqué borlas! Pero sobretodo iqué concurrencia! ¡qué gentío! iqué devoción! Si éste no es un objeto de edificación el más recomendable, ¿dónde iremos a buscarlos?...

Hasta aquí, la crítica es la misma que los ilustrados hacían de las procesiones, del boato, los adornos, la pompa, las exterioridades todas que nada tienen que ver con la auténtica devoción, la actitud del gentío que lo mismo iba a ver a una infeliz acorozada por el Santo Oficio o a un ahorcado en la Plaza de la Cebada que a oír uno de los comediones disparatados de la época, y que seguía una procesión religiosa como si fuera una fiesta de Carnaval. Lejos de exaltar la auténtica piedad, las procesiones la pervertían. Estas fiestas y procesiones llamadas religiosas corrompían al pueblo, lo embrutecían con espectáculos impíos y vulgares. Aún más en el caso del Rosario a que se refieren la Carta y el Soneto, puesto que quienes tomaban parte en la procesión eran los mismos actores que el pueblo veía en el teatro hacer papeles de tiranos y traidores, de tramposos y disolutos, excitando la risa o las emociones más bajas, y que ahora, "trocados los oficios del arte histriónica", pretendían excitar la devoción. El papel de la Virgen Santísima lo hacía la primera dama, a quien el público aplaudía en papeles profanos y poco piadosos. La Carta concluye con una frase que es un resumen de la intención satírica y didáctico-moral de su autor: "Ayúdeme Vmd., pues, a ce- 
lebrarla [la gracia], y congratúlese conmigo de la excelencia de nuestras instituciones, que saben también conciliar la piedad con el entretenimiento, y sacar, por decirlo así, sabrosa miel de devoción de las amargas y venenosas flores del vicio y la impiedad". Y como epílogo de la Carta sigue el Soneto -que no ha vuelto a publicarse desde entonces, que nosotros sepamos:

\section{EPílogo}

Éstos que viste ayer, Fabio, fingiendo con tristes casos del amor voltario, la hinchazón del orgullo estrafalario, del fraude y la traición el caos horrendo,

hoy por las calles su rumor siguiendo contritos el magnífico Rosario, su piedad, su fervor extraordinario van *a María humildes ofreciendo.

¡Notable exemplo de virtud, que todos ven con espanto, admiran con ternura al paso de la mística comparsa!

Sólo un chispero gastador de apodos dixo, con más donaire que locura:

"Al fin en este gremio todo es farsa".

Si el Soneto es inferior a las dos "Sátiras a Arnesto", publicadas en El Censor poco antes - sin firma, igualmente-, su interés como documento social y moral es el mismo. Al moralista neoclásico le parece poco decoroso mezclar lo religioso con lo profano, como le parece de mal gusto mezclar las distintas especies de estilo. Pero ésta no sería más que una reacción superficial. Al hombre profundamente religioso que es Jovellanos, le choca que los clérigos se acomoden a las costumbres y gustos más bajos del día, permitiendo que un misterio divino se convierta en representación chabacana, en vez de elevar el gusto público mediante la enseñanza de la escritura divina. Jovellanos y muchos de sus contemporáneos ilustrados, lejos de coincidir con Voltaire y los enciclopedistas franceses en su propósito de "écraser l'infâme", desean fortalecer la religión purificándola, y creen que los que tienen a su cargo la conciencia de los fieles deben afanarse por lograr la aplicación directa de las palabras divinas a la conducta humana. La "farsa" del Soneto es la falsa devoción que perjudica al alma individual y colectiva y constituye al mismo tiempo un gran obstáculo para la ilustración nacional. La Ilustración es un credo que invade a toda la Europa del siglo xvrII, una fe que se compendia en estas frases que escribió Jovellanos a Godoy en sus cartas "Sobre el medio de promover la prosperidad nacional" (1796): "En este orden de prosperidad de una nación tiene el primer lugar la ilustración, y se presenta a mis ojos como la primera fuente de toda prosperidad, como la única, puesto que una nación ilus- 
trada tendrá en su mano conocer y alcanzar todas las demás causas subalternas de su prosperidad" ( $B A E$, t. 86, p. 197).

Sobre la ilustración pública compuso Jovellanos varios discursos y oraciones, reglamentos y programas, destinados particularmente a su Instituto Asturiano. En la "Oración inaugural" dirige a sus compatriotas asturianos estas sentidas palabras: "Hay por ventura sobre la tierra cosa más noble ni más preciosa que la sabiduría?" Y aunque se propone promover en el Instituto los conocimientos útiles, insiste repetidamente en la necesidad de unir el estudio de las humanidades con el de las ciencias, porque "si las ciencias esclarecen el espíritu, la literatura le adorna...; si aquéllas le enriquecen, ésta pule y avalora sus tesoros; las ciencias rectifican el juicio y le dan exactitud y firmeza; la literatura le da discernimiento y gusto, y le hermosea y perfecciona... ; a su inmensa jurisdicción pertenece cuanto tiene relación con la expresión de nuestras ideas" ( $B A E$, t. $4^{6}$, p. 330). De igual manera, al principio de su "Reglamento para el Colegio de Calatrava", Jovellanos encarece la necesidad de las humanidades, y dice que sin una sólida instrucción en este ramo no se puede esperar ningún fruto en las facultades mayores, puesto que "el buen gusto, la buena y sana crítica, el exacto y preciso estilo de hablar y de escribir, el discernimiento de las doctrinas y opiniones, el amor a los buenos libros y el hastío y horror a los malos penden casi del todo de este estudio preliminar" (ibid., p. 16g). Sobre este primer sentido del término "humanismo" - el estudio de las lenguas y las grandes obras literarias de la Antigüedad- están de acuerdo los humanistas de todos los tiempos. Alfonso Reyes hablaba asimismo de la conciliación entre la Economía y las Humanidades en su “Homilía por la cultura”. Esa conciliación -decía- "contenta ciertamente nuestros viejos anhelos platónicos, acariciados desde la infancia, y hasta nos convida a soñar en un mundo mejor, donde llegue a resolverse la antinomia occidental entre la vida práctica y la vida del espíritu... Por encima de todas las especialidades y profesiones limitadas a que nos obliga la complejidad de la época, hay que salvar aquélla que Guyau y Rodó han llamado la profesión general de ser hombre". Esto mismo lo había dicho Juan Luis Vives siglos antes en una carta a Erasmo, insistiendo en la importancia de las humanidades para todos, y sobre todo para los españoles: "Así se suavizarán —escribía-, así se despojarán de ciertas concepciones rudas de la vida, de las que están imbuidos sus espíritus, tan penetrantes pero jay! tan poco versados en humanidades" (cit. por Gregorio Marañón, Luis Vives, Madrid, 1942, p. 138). Vives, Jovellanos, Reyes vienen a decir lo mismo: que las humanidades nos proporcionan medios de cumplir con nuestro destino y con nuestra obligación de hacernos hombres.

Para Jovellanos, sin embargo, el humanismo no es tanto un re- 
torno a la Antigüedad clásica griega y romana cuanto un retorno a la antigüedad española, un esfuerzo por restaurar los viejos tiempos en que la nobleza y el clero sentían la debida responsabilidad ante las demás clases que dependían de ellos. En sus páginas se acentúan, desde luego, las notas características de la segunda mitad del siglo xviII, y se repiten las abstracciones ineludibles del momento: "la humanidad", "la Naturaleza", "la felicidad pública". Pero Jovellanos ha llegado a estas abstracciones tras innumerables observaciones directas de la realidad nacional, llevadas a cabo durante los muchos años en que recorrió a caballo los malos caminos de Castilla y Asturias, alojándose en incómodas posadas, levantándose al amanecer para oír misa antes de emprender otra ardua jornada en que volvería a mirar, a indagar, a escudriñar, a hablar con los habitantes sobre las muchas cosas que le interesaban: la historia del lugar, el habla de los lugareños, los cultivos e industrias, las escuelas y parroquias, los archivos y los monumentos artísticos. A Jovellanos le preocupaba el hombre individual, cómo vivía, cómo se divertía, qué medios tenía para perfeccionarse, para medrar, para aumentar la felicidad pública, sí, pero primero la suya propia. Le parecía absurdo hablar tanto de la felicidad pública y obrar tan poco por la felicidad de los particulares; estas ideas, decía en una de sus cartas a Antonio Ponz, "me parecen un poco chinescas; ponen al pueblo, esto es, a la clase más necesaria y digna de atención, en una condición miserable; establecen la opulencia de los ricos en la miseria de los pobres, y levantan la felicidad del Estado sobre la opresión de los miembros del Estado mismo" ( $B A E$, t. 5o, p. 294). Aunque aquí habla de los labradores, es el labrador lo que más le importa. Quiere levantar el nivel material de su vida, pero también dignificarlo como persona. Más que un sistema de ideas abstractas, la Ilustración española es un esfuerzo inmenso y constante por reformar la vida individual y colectiva de los españoles, por conseguir la compenetración de la tradición nacional viva y profunda con la ciencia extranjera moderna, de la primitiva fe cristiana con el humanismo del Renacimiento, por lograr la reafirmación del valor y la dignidad del hombre concreto individual y, al mismo tiempo, la educación del hombre como ciudadano que cumple con sus deberes sociales y políticos.

A Jovellanos y a Vives les tocó vivir en épocas de crisis espiritual, de una gran inquietud y curiosidad por toda clase de experiencias y conocimientos, de un inmenso afán por ensanchar el horizonte humano. Eran, forzosamente, tiempos de gran riesgo para un espíritu crítico independiente, y hasta en Brujas eran tan difíciles -según escribía Vives a su maestro y amigo Erasmo-, que no se podía hablar ni callar sin peligro. Más de dos siglos después se quejaba de lo mismo Moratín a su amigo Forner en una carta escrita desde Montpellier, el 23 de marzo de 1789: “. . Créeme, Juan; la edad en 
que vivimos nos es muy poco favorable; si vamos con la corriente y hablamos el lenguaje de los crédulos, nos burlan los extranjeros, y aun dentro de casa hallaremos quien nos tenga por tontos; y si tratamos de disipar errores funestos y enseñar al que no sabe, la santa y general Inquisición nos aplicará los remedios que acostumbra" (Obras póstumas de Moratin, Madrid, 1867, t. 2, p. 79).

Pero estas confesiones se hacían únicamente en cartas a amigos intimos; la crítica que se publicaba era cautelosa, ambigua o anónima. Jovellanos la hacía en sátiras sin firma, como el Soneto que publicamos, o con más frecuencia en sus Diarios y en su correspondencia, que escribía pensando más en las generaciones venideras que en sus propios contemporáneos. La perspectiva desde la cual veía la patria anhelada y soñada era la de un porvenir lejano pero previsible. La naturaleza del espíritu humano, decía en una de sus cartas a Godoy, es "progresiva", y no mejora sino por grados. Estaba persuadido, pues, de que el medio más seguro de no hacer nada por el bien de una nación era querer hacerlo todo de una vez. Lo que urgía era preparar bien el terreno y luego sembrar, es decir, instruir y educar: la cosecha -la ilustración y la felicidad de todos los hombres- vendría con el tiempo.

Observaba Marañón a propósito de Vives que el intelectual consciente y crítico es un eterno expatriado, puesto que nunca llega a vivir en la patria tal como la desea y la sueña. Vives y Jovellanos fueron expatriados de distinta manera: Vives pasó la mayor parte de su vida fuera de su patria, añorándola, y Jovellanos vivió fuera de su tiempo, vislumbrando a la patria, amada tan fervientemente, en otra época mejor y por venir. Fue el humanismo de Jovellanos un humanismo palpitante y vivido, que le sirvió de norma en todos sus oficios y ocupaciones; sintió el mismo afán de conocimiento que habían sentido los primeros y más grandes humanistas, pero siempre -y en esto fue fiel al espíritu de su época- con la finalidad de dar a conocer lo que había aprendido a discípulos y amigos, a Sociedades y Consejos, para que sus observaciones, investigaciones y enseñanzas fuesen útiles, por siempre, a todos los españoles. Lo esencial del humanismo de Jovellanos se resume en estas palabras suyas, que podrían servir de lema a toda su vida: "De la obligación con que nace todo hombre de concurrir al bien de sus semejantes, nace la de consagrar sus luces a este grande objeto..."

Edith F. Helman 